\title{
Gamma Knife Surgery for Residual or Recurrent Craniopharyngioma After Surgical Resection: A Multi-institutional Retrospective Study in Japan
}

Takahiko Tsugawa ${ }^{1}$, Tatsuya Kobayashi ${ }^{1}$, Toshinori Hasegawa ${ }^{2}$, Yoshiyasu Iwai ${ }^{3}$, Shigeo Matsunaga ${ }^{4}$, Masaaki Yamamoto ${ }^{5}$, Motohiro Hayashi ${ }^{6}$, Hiroyuki Kenai ${ }^{7}$, Tadashige Kano ${ }^{8}$, Hisae Mori ${ }^{9}$, Osamu Nagano $^{10}$, Seiko Hasegawa ${ }^{11}$, Akira Inoue ${ }^{12}$, Yasushi Nagatomo ${ }^{13}$, Shinji Onoue ${ }^{14}$, Manabu Sato ${ }^{15}$, Soichiro Yasuda 16

1. Neurosurgery, Nagoya Radiosurgery Center, Nagoya Kyoritsu Hospital, Nagoya, JPN 2. Neurosurgery, Komaki City Hospital, Komaki, JPN 3. Neurosurgery, Osaka City General Hospital, Osaka, JPN 4. Neurosurgery, Yokohama Rosai Hospital, Yokohama, JPN 5. Neurosurgery, Mito Gammahouse, Katsuta Hospital, Hitachinaka, JPN 6. Neurosurgery, Tokyo Women's Medical University Hospital, Tokyo, JPN 7. Neurosurgery, Nagatomi Neurosurgical Hospital, Oita, JPN 8. Neurosurgery, Kano Neurosurgery Clinic, Maebashi, JPN 9. Neurosurgery, National Cerebral and Cardiovascular Center, Suita, JPN 10. Neurosurgery, Chiba Cerebral and Cardiovascular Center, Ichihara, JPN 11. Neurosurgery, Kuroishi General Hospital, Kuroishi, JPN 12. Neurosurgery, Yamagata Prefectural Central Hospital, Yamagata, JPN 13. Neurosurgery, Kouseikai Takai Hospital, Tenri, JPN 14. Neurosurgery, Ehime Prefectural Central Hospital, Matsuyama, JPN 15. Neurosurgery, Rakusai Shimizu Hospital, Kyoto, JPN 16. Neurosurgery, Shiroyama Hospital, Habikino, JPN

Corresponding author: Takahiko Tsugawa, tuntun1965@hotmail.com

Received 01/03/2020

Review began 01/08/2020 Review ended 01/18/2020 Published 02/12/2020

\section{() Copyright 2020}

Tsugawa et al. This is an open access article distributed under the terms of the Creative Commons Attribution License CC-BY 4.0., which permits unrestricted use, distribution, and reproduction in any medium, provided the original author and source are credited.

\section{Abstract \\ Objective}

The optimal treatment for a craniopharyngioma has been controversial. Complete resection is ideal, but it has been difficult to obtain total resection in many cases because of intimate proximity to critical structures such as the optic pathway, hypothalamus, and pituitary gland. A growing number of studies have demonstrated the utility of radiosurgery in controlling residual or recurrent craniopharyngioma. However, most of them are small series. The aim of this multi-institutional study was to clarify the efficacy and safety of Gamma Knife (Elekta, Stockholm, Sweden) surgery for patients with a craniopharyngioma.

\section{Methods}

This was a multi-institutional retrospective study by 16 medical centers of the Japan Leksell Gamma Knife Society. Data on patients with craniopharyngiomas treated with Gamma Knife Surgery (GKS) between 1991 and 2013 were obtained from individual institutional review board-approved databases at each center. A total of 242 patients with craniopharyngioma were included in this study. The mean age of the patients was 41 (range, 3 to 86) years. The median follow-up time was 61.4 months (range, 3 to 180 months). The mean radiosurgery target volume was $3.1 \mathrm{ml}$ (range, $0.03-22.3 \mathrm{ml}$ ), and the mean marginal dose was $11.4 \mathrm{~Gy}$ (range, 8-20.4 Gy).

\section{Results}

Two-hundred twenty patients were alive at the time of the last follow-up visit. The three-, five-, and 10-year overall survival rates after GKS were $95.4 \%, 92.5 \%$, and $82.0 \%$, respectively. The three-, five-, and 10 -year progression-free survival rates after GKS were $73.1 \%, 62.2 \%$, and $42.6 \%$ respectively. The rate of radiationinduced complications was $6.2 \%$.

\section{Conclusion}

GKS is effective for controlling the tumor growth of craniopharyngiomas with an acceptable complication rate.

Categories: Radiation Oncology, Neurosurgery

Keywords: craniopharyngioma, radiosurgery, gamma knife

\section{Introduction}

Craniopharyngioma is a rare benign tumor thought to be derived from embryological remnants of the primitive craniopharyngeal duct or Rathke's pouch. The incidence of craniopharyngioma is reported to be 0.13 in 100000, accounting for approximately $1 \%-4 \%$ of all central nervous system (CNS) neoplasms in adults and $5 \%-10 \%$ in children. The age of onset demonstrates a bimodal peaked distribution of 5-15 and $45-55$ years old [1-3].

The optimal treatment for craniopharyngioma remains controversial. Surgery is usually considered the 


\section{Cureus}

treatment of choice. It offers rapid symptom relief and pathological confirmation, and when total resection is achieved, long-term local control can be expected [4]. However, despite the advances in microsurgical and endoscopic techniques, it is difficult to achieve total resection in more than a few cases because of the intimate relationship with surrounding critical structures such as the hypothalamus, optic apparatus, and pituitary gland [5-7]. Several studies have reported the usefulness of Gamma Knife Surgery (GKS) for controlling craniopharyngiomas with a reduction in the complication rate; however, most have been small series [8-14].

We herein report a multi-institutional study (the largest series to date) on the efficacy of GKS for craniopharyngiomas.

\section{Materials And Methods}

Patient characteristics

This was a multi-institutional retrospective study conducted by 16 hospitals of the Japan Leksell Gamma Knife Society. The data of patients with craniopharyngiomas treated with GKS between 1991 and 2013 were obtained from individual institutional review board-approved databases at each center. A total of 242 patients with craniopharyngiomas were included in this study. The patient characteristics are shown in Table 1 . 


\section{Cureus}

\begin{tabular}{|c|c|c|c|}
\hline & Value & Range & $\%$ \\
\hline \multicolumn{4}{|l|}{ Age at GKS (yrs) } \\
\hline mean & 41 & $3-86$ & \\
\hline under 16 & 40 & & 16.5 \\
\hline \multicolumn{4}{|l|}{ Gender } \\
\hline male & 127 & & 52.5 \\
\hline female & 115 & & 47.5 \\
\hline \multicolumn{4}{|l|}{ Operation } \\
\hline total resection & 49 & & 20.2 \\
\hline partial resection & 182 & & 75.2 \\
\hline biopsy & 11 & & 4.5 \\
\hline \multicolumn{4}{|l|}{ Previous treatment } \\
\hline previous multiple operations & 71 & & 29.8 \\
\hline previous radiation & 9 & & 3.7 \\
\hline \multicolumn{4}{|l|}{ KPS } \\
\hline $80 \leqq$ & 219 & & 90.5 \\
\hline \multicolumn{4}{|l|}{ Tumor nature } \\
\hline solid & 110 & & 454.4 \\
\hline cystic & 68 & & 28.1 \\
\hline mixed & 64 & & 26.4 \\
\hline \multicolumn{4}{|l|}{ Tumor volume (ml) } \\
\hline mean & 3.1 & $0.03-22.3$ & \\
\hline \multicolumn{4}{|l|}{ Tumor involvement site } \\
\hline sellae-supra sellae & 189 & & 78.1 \\
\hline pro sellae & 19 & & 7.9 \\
\hline retro sellae & 9 & & 3.7 \\
\hline 3rd ventricle & 45 & & 18.6 \\
\hline \multicolumn{4}{|l|}{ Visual disturbance } \\
\hline VA decrease & 132 & & 54.5 \\
\hline VF defect & 112 & & 46.3 \\
\hline \multicolumn{4}{|l|}{ Pituitary function } \\
\hline hypopituitarism & 133 & & 55 \\
\hline diabetes insipidus & 100 & & 41.3 \\
\hline
\end{tabular}

\section{TABLE 1: Demographics of patients with craniopharyngioma}

GKS = Gamma Knife Surgery, KPS = Karnofsky Performance Status, VA = Visual Acuity, VF = Visual Defect

All patients underwent surgical resection (including biopsy cases) before GKS and had histological confirmation of a craniopharyngioma. The mean duration between the diagnosis and the first GKS was 33.7 months (range 0-450). The first operation was total resection in 48 (19.8\%), partial resection in $182(75.2 \%)$ 
and biopsy in 11 (4.5\%). Nine patients (3.7\%) underwent conventional fractionated radiotherapy before the first GKS.

The nature of the tumor was solid in 110 (45.5\%), cystic in 68 (28.1\%), and mixed in 64 (26.4\%) cases. Onehundred thirty-two patients (54.5\%) had visual disturbance, and $153(63.2 \%)$ patients had hypopituitarism at the first GKS. The mean age of the patient was 41.0 years (range 3-86 years old). Of the 242 patients, 40 (16.5\%) were under 16 years old. The median Karnofsky Performance Status (KPS) score at the first GKS was 90.

The target tumor involvement site at the first GKS was sellae and/or supra sellae in 189 (78.1\%), pro sellae in 19 (7.9\%), retro sellae in 9 (3.7\%), and third ventricle in 45 (18.6\%).

\section{Radiosurgery technique}

Stereotactic radiosurgery was conducted using a Leksell Gamma Knife model B, C, 4C, and Perfexion (Elekta $\mathrm{AB}$, Stockholm, Sweden) at each participating center.

A Leksell model G stereotactic coordinate frame (Elekta $\mathrm{AB}$ ) was fixed to the patient's head under local anesthesia supplemented by intramuscular and/or intravenous sedation. Stereotactic magnetic resonance imaging (MRI) was performed to define the tumor location and shape. Images were transferred via an ethernet connection to the Gamma Knife computer workstation (KULA system and GammaPlan; Elekta AB), where treatment planning was done. Contrast-enhanced MRI was used for the identification of the irregular borders of the neoplasm. The choice of the marginal irradiation dose depended on the tumor volume and the spatial relationship between the tumor and the adjacent anatomical structures, especially the visual pathway. After dose planning, patients were treated with Gamma Knife Units B, C, 4C, or Perfexion (AB Elekta) at participating centers.

The median tumor volume was $3.1 \mathrm{~cm}^{3}$ (range, $0.03-22.3 \mathrm{~cm}^{3}$ ). The median maximum dose was $21.8 \mathrm{~Gy}$ (range, 8-36 Gy), the median margin dose was $11.4 \mathrm{~Gy}$ (range, 8-20.4 Gy), and the amount irradiated to the optic pathway varied from 1.6 to $14 \mathrm{~Gy}$ (median, $7.3 \mathrm{~Gy}$ ).

\section{Follow-up}

All patients underwent both clinical and radiological evaluations at each participating institute, including a neurological examination, visual examination, hormonal evaluation, and MRI regularly performed at threeto six-month intervals after GKS. At each imaging analysis, the tumor response was categorized into one of four results: complete response (CR, tumor disappearance), partial response ( $P R,>50 \%$ reduction of the tumor volume), no change (SD, stable disease), and progression (PG, $>25 \%$ increase in tumor volume). If new tumors or progression of the treated tumors were noted during follow-up, appropriate additional treatment, including repeat GKS, other types of radiation, or surgical resection, were offered.

\section{Statistical analyses}

The overall survival (OS) and progression-free survival (PFS) after the first GKS was calculated using the Kaplan-Meier estimator. The log-rank test was utilized to compare the survival differences between groups. To analyze factors that correlated with the PFS, we assessed the following data: age, sex (male vs. female), tumor nature, tumor location, tumor volume, maximum dose, and marginal dose. P-values $<0.05$ were considered statistically significant. The statistical analysis was performed using the JMP software program, version 7 (SAS Institute Inc., Cary, North Carolina).

\section{Results}

The median clinical follow-up period was 61.4 months (range, 3-180 months), and the median radiological follow-up period was 57.3 months (range, 3-205 months).

\section{The OS}

Two-hundred twenty patients (90.9\%) were alive at the last follow-up time visit, with 22 (9.1\%) deaths. Of these 22 patients, 11 (4.5\%) died of tumor progression. The remaining 11 died of another reason such as lung cancer, pneumonia, and renal failure. The three-, five-, and 10-year overall survival rates after the first GKS were 95.4\%, 92.5\%, and 82.0\%, respectively (Figure 1). 


\section{Cureus}

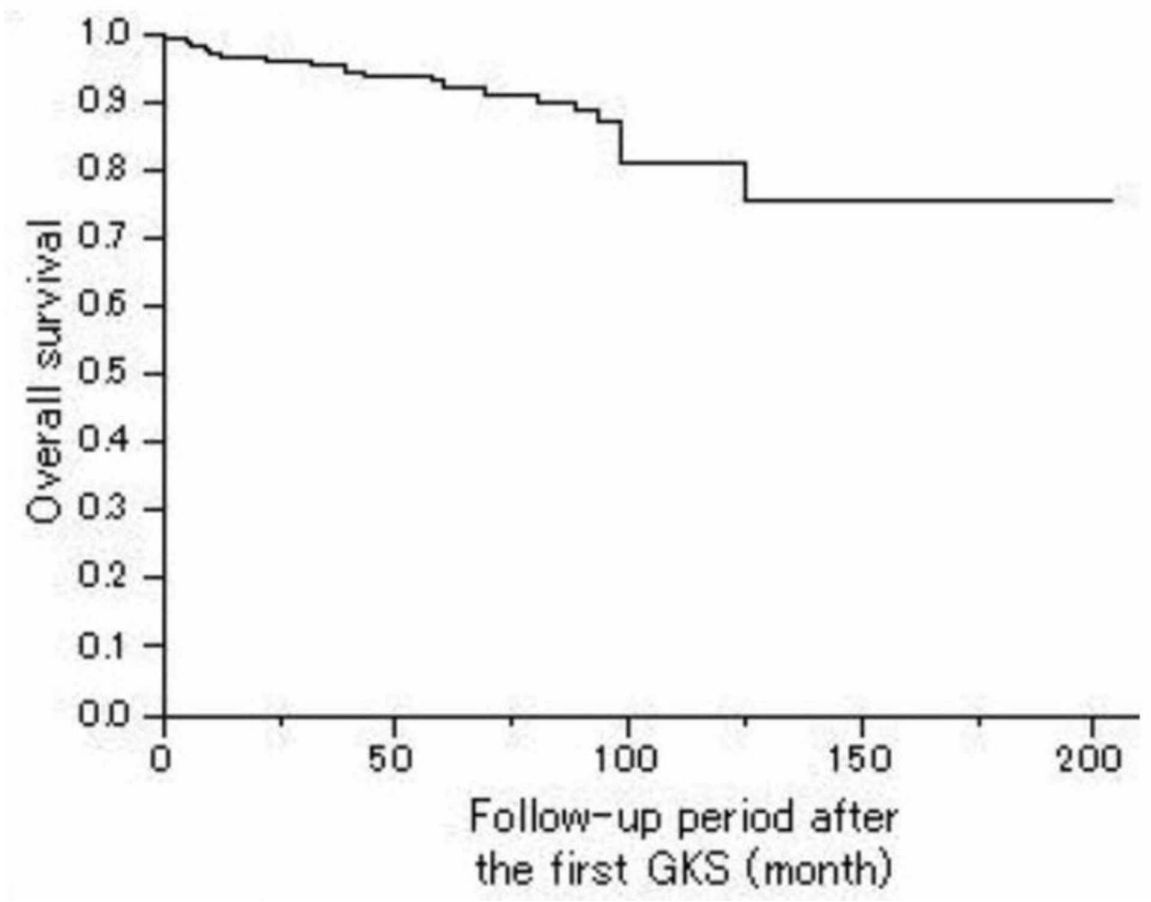

\section{FIGURE 1: Overall survival}

Kaplan-Meier curve showing the OS of 242 patients with a craniopharyngioma. The actual three-, five-, and 10 -year OS rates after the first GKS was $95.4 \%, 62.5 \%$, and $82.0 \%$, respectively.

OS = Overall Survival, GKS = Gamma Knife Surgery

The overall survival showed no statistically significant difference according to the types of the first surgical operation (Figure 2).

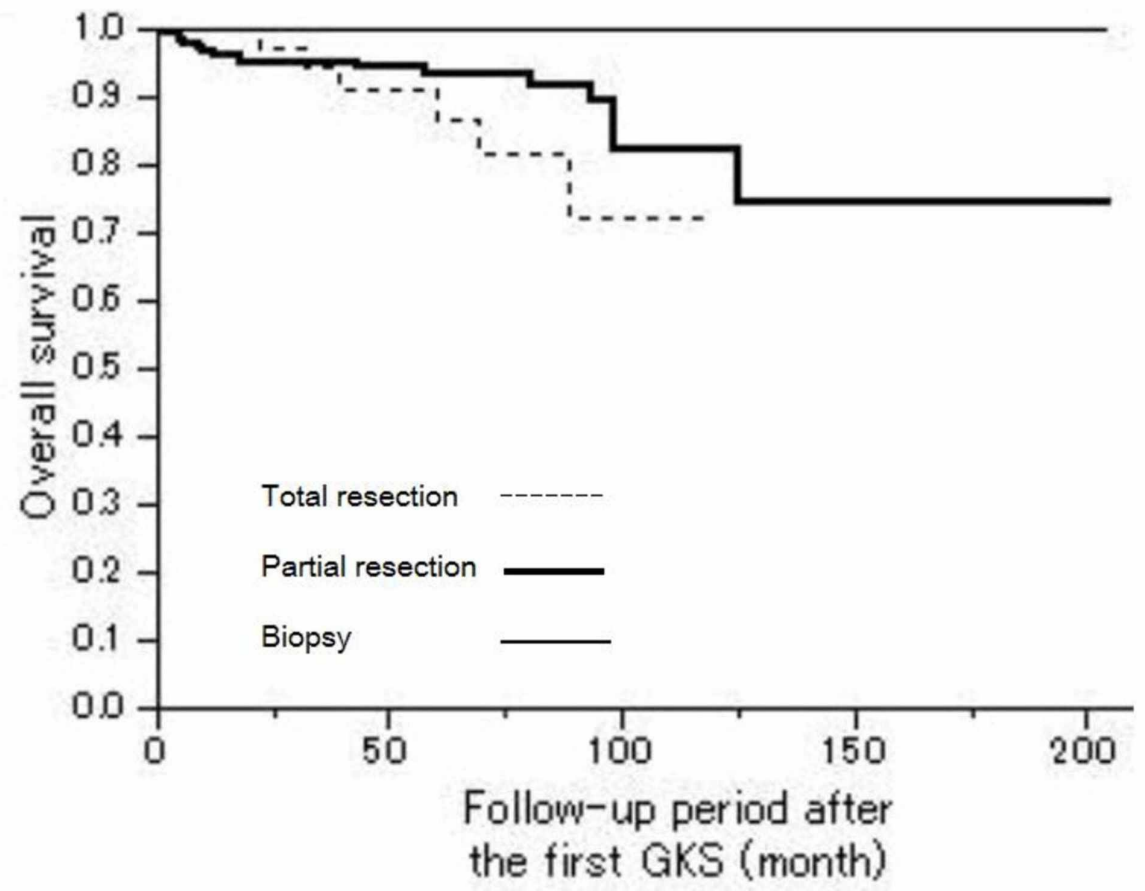

FIGURE 2: Overall survival depending on the type of the first operation

Kaplan-Meier OS curves showed no statistically significant difference in relation to the types of the first operation (Log-rank, $\mathrm{P}=0.1629$ ). 


\section{Cureus}

$\mathrm{P}<0.05$ statistically significant, OS $=$ Overall Survival, GKS = Gamma Knife Surgery

The median KPS score at the last follow-up visit was 90.

\section{Tumor control}

The three-, five-, and 10-year PFS rates after the first GKS were $73.1 \%, 62.2 \%$, and $42.6 \%$, respectively (Figure 3).

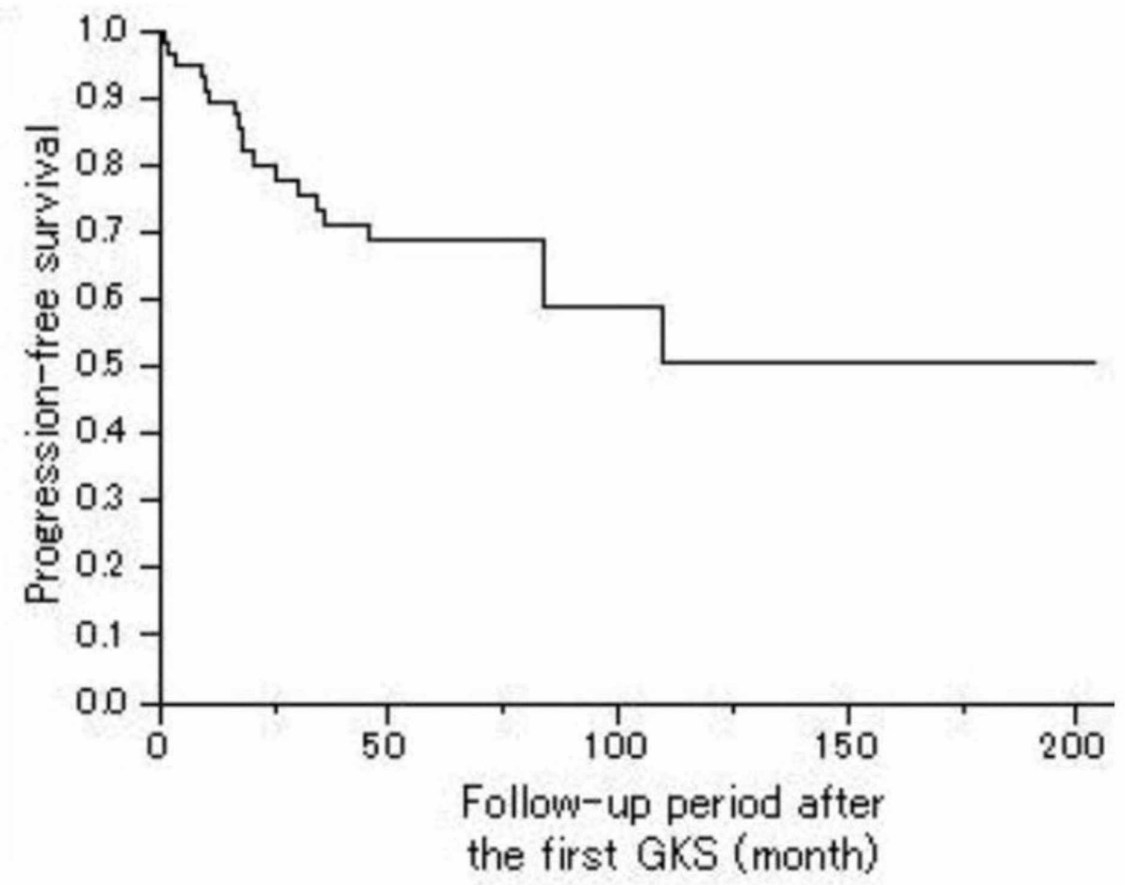

\section{FIGURE 3: Progression-free survival}

Kaplan-Meier curve showing the PFS of 242 patients with a craniopharyngioma. The actual three-, five-, and 10 -year PFS rates after the first GKS was $73.1 \%, 62.2 \%$, and $42.6 \%$, respectively.

PFS = Progression-Free Survival, GKS = Gamma Knife Surgery

The PFS showed no statistically significant difference according to the types of the first surgical operation (Figure 4). 


\section{Cureus}

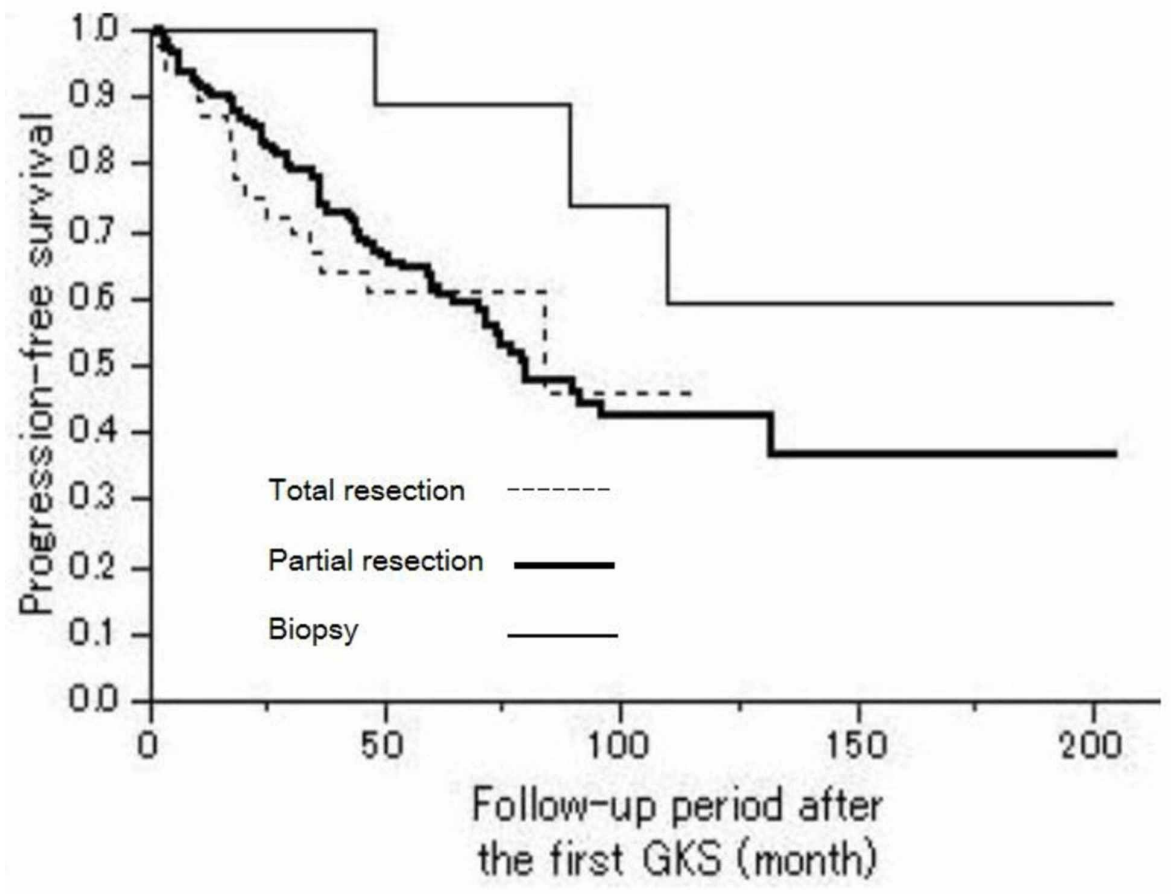

FIGURE 4: Progression-free survival depending on the types of the first operation

Kaplan-Meier PFS curves showed no statistically significant difference in relation to the types of the first operation (Log-rank, $\mathrm{P}=0.2626$ ).

$\mathrm{P}<0.05$ statistically significant, PFS = Progression-Free Survival, GKS = Gamma Knife Surgery

A univariate analysis showed that the tumor volume and tumor location (extending to the third ventricle) were significantly correlated with the PFS (Table 2).

\begin{tabular}{|l|l|}
\hline Factor & Univariate P-value \\
\hline Sex & 0.8201 \\
\hline Age $(<16)$ & 0.7652 \\
\hline Resection (total resection or not) & 0.7568 \\
\hline Tumor volume & $0.0102^{*}$ \\
\hline Tumor nature & 0.2721 \\
\hline Location (extension to third ventricle) & $0.0317^{*}$ \\
Marginal dose & 0.5134 \\
\hline Maximum dose & 0.7674 \\
\hline
\end{tabular}

\section{TABLE 2: Univariate analysis of prognostic factors related to PFS}

$\mathrm{P}<0.05$ statistically significant; PFS = Progression-Free Survival

The MRI findings of the response of the tumor treated by the first GKS were CR in 19 (7.9\%), PR in 82

(33.9\%), NC in 47 (19.4\%), and PG in 74 (30.6\%). In addition to local recurrence, new tumors

developed outside of the irradiated area in 22 (9.1\%) cases. Figure 5 depicts an illustrative case. 


\section{Cureus}

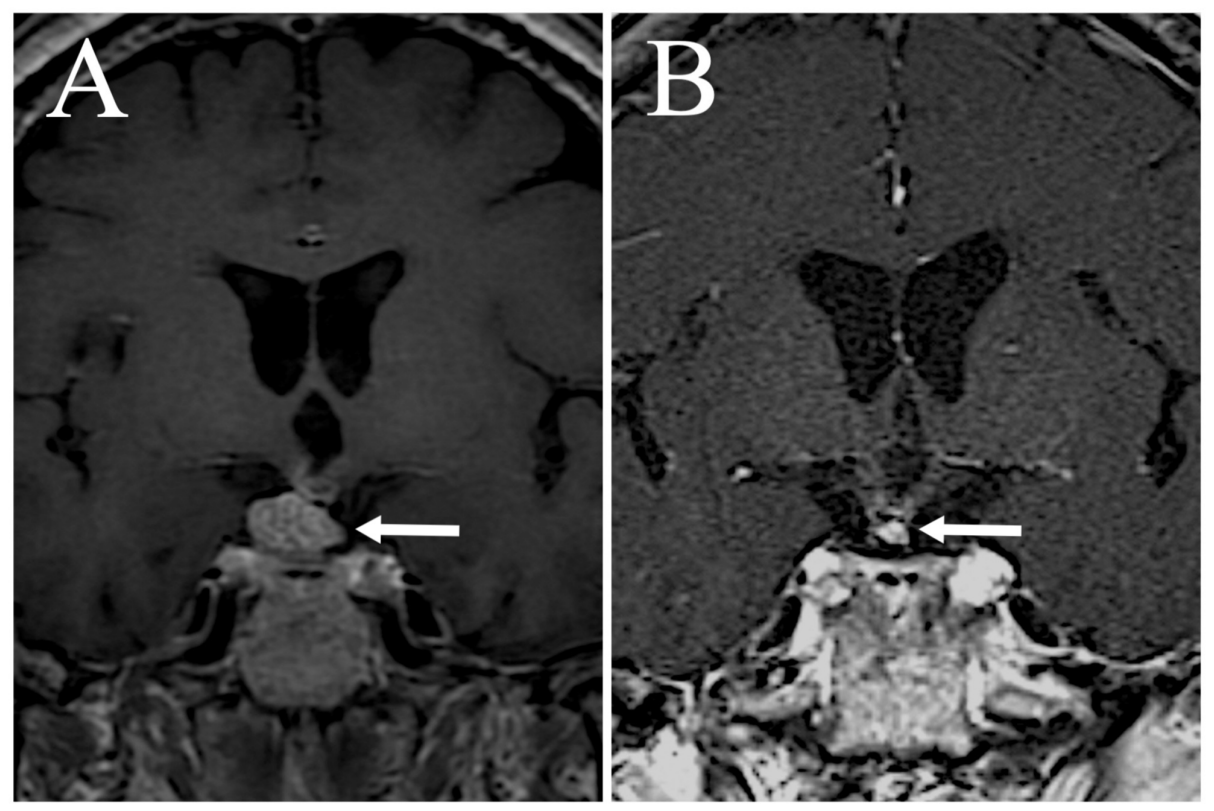

\section{FIGURE 5: Illustrative case}

A 66-year-old female. Coronal T1-weighted magnetic resonance imaging (MRI) with gadolinium (Gd) enhancement depicting a recurrent craniopharyngioma during GKS (A). The recurrent tumor was treated with a margin dose of 11 Gy. Follow-up MRI with Gd enhancement performed 40 months after GKS showing tumor regression (B).

GKS = Gamma Knife Surgery; MRI = Magnetic Resonance Imaging

\section{Patient management}

In the course of tumor management, nearly half of the cases required multiple treatments. The total number of Gamma Knife procedures applied was one in 139 cases (16.1\%), two in 59 cases $(24.4 \%)$, three in 28 cases $(11.6 \%)$, and $\geqslant$ four in 11 cases $(4.5 \%)$. The total number of surgeries performed was one in 140 cases (16.5\%), two in 60 cases (24.8\%), three in 28 cases (11.6\%), and $\geqslant$ four in 11 cases (11.6\%). The treatment for a recurrent tumor after GKS was a repeat GKS in 43 (17.8\%), an operation in 51 (21.1\%), and irradiation without GKS in $14(5.8 \%)$

\section{The hormonal function}

One-hundred fifty-three patients (63.2\%) had anterior pituitary dysfunction, and 100 (41.3\%) had diabetes insipidus (DI) at the time of the first GKS. The anterior pituitary function at the last follow-up visit improved in one and deteriorated in 10 as compared with the function at the first GKS. Fifteen patients showed deterioration of the posterior pituitary function, whereas two who had DI were able to discontinue the medication at the last follow-up visit. Of the 15 patients who presented new DI, 12 cases developed after additional surgical resection.

\section{The visual function}

One-hundred thirty-two patients (62.8\%) had disturbance of visual acuity, and 112 (46.2\%) had visual field defects at the time of the first GKS. At the last follow-up visit, the visual acuity was improved in seven cases, and visual field defects were improved in 18 cases, whereas eight patients showed deterioration of the visual acuity and eight patients showed deterioration of their visual field.

\section{Adverse effects}

Fifteen patients developed radiation-induced side effects, including visual deterioration in four, deterioration of the anterior pituitary function in eight, DI in three, hypothalamic dysfunction (obesity) in one, brain edema in one, and hydrocephalus in one. The rate of radiation-induced complications was $6.2 \%$.

\section{Discussion}

While a craniopharyngioma is histologically benign, corresponding to World Health Organization (WHO) grade I, as it grows, it begins to aggressively interact with the surrounding critical organs, such as the optic pathway, pituitary gland, vascular structures, and hypothalamus, causing impairment. The optimal 
treatment for a craniopharyngioma has been controversial. The difficulty in planning the treatment strategy for craniopharyngioma is mostly due to the intimate anatomical relationship with surrounding critical structures [5-7].

Because the life expectancy of the patients harboring this tumor may be extended with appropriate management, complications associated with treatment should be reduced as much as possible. Aggressive surgery offers a greater chance of achieving total resection, which leads to a favorable local control rate, but it may cause unacceptable complications such as visual disturbance, pituitary dysfunction, and cognitive disturbance [15-17]. The treatment strategy should be determined after considering that the tumor may recur after the operation even if gross total resection is achieved [18-19].

Fractionated external-beam radiation following partial removal is effective for controlling tumor growth and improving patient survival [20-21]. However, there are still issues remaining to be addressed, such as tumor regrowth and late-onset radiation-related visual, hypothalamic, and endocrine complications [22-23].

Recently, with the development of stereotactic radiation techniques, partial resection followed by stereotactic irradiation has been accepted as a viable treatment approach for craniopharyngioma (Table 3) [8-14,24-27].

\begin{tabular}{|c|c|c|c|c|c|c|c|}
\hline $\begin{array}{l}\text { Author \& } \\
\text { year }\end{array}$ & $\begin{array}{l}\text { Radiation } \\
\text { therapy }\end{array}$ & $\begin{array}{l}\text { No. of } \\
\text { patients }\end{array}$ & $\begin{array}{l}\text { Mean tumor volume } \\
\text { (ml) }\end{array}$ & Mean marginal dose (Gy) & $\begin{array}{l}\text { F/U } \\
\text { (month) }\end{array}$ & $\begin{array}{l}\text { Tumor control } \\
\text { rate }(\%)\end{array}$ & $\begin{array}{l}\text { Morbidity } \\
(\%)\end{array}$ \\
\hline $\begin{array}{l}\text { Ulfarsson et } \\
\text { al. } 2002\end{array}$ & GKS & 21 & 8 & 5 & 13 & 36 & 19 \\
\hline $\begin{array}{l}\text { Yomo et al. } \\
2009\end{array}$ & GKS & 18 & 3.5 & 11.5 & 26 & 94 & 0 \\
\hline $\begin{array}{l}\text { Niranjan et } \\
\text { al. } 2010\end{array}$ & GKS & 46 & 1 & 13 & 62 & 68 & 17.4 \\
\hline $\begin{array}{l}\text { Lee et al. } \\
2014\end{array}$ & GKS & 137 & 5.5 & 12 & 53 & 69 & 11.7 \\
\hline $\begin{array}{l}\text { Dho et al. } \\
2018\end{array}$ & GKS & 35 & 1.4 & $\begin{array}{l}15 \text { (single-session), 18( } \\
\text { fractionated) }\end{array}$ & 71.9 & 63 (5 yrs) & N/A \\
\hline $\begin{array}{l}\text { Iwata et al. } \\
2012\end{array}$ & CKS & 43 & $\begin{array}{l}0.5 \text { (single-session), } \\
2.2 \text { (fractionated) }\end{array}$ & $\begin{array}{l}14 \text { (single-session), 16-25 } \\
\text { (fractionated) }\end{array}$ & 40 & 85 (5 yrs) & 2.3 \\
\hline $\begin{array}{l}\text { Harrabi et al. } \\
2014\end{array}$ & FSRT & 55 & 31.2(PTV) & $52.2(1.8-2$ per day & 128 & 92 (10 yrs) & 3.6 \\
\hline $\begin{array}{l}\text { Present } \\
\text { study }\end{array}$ & GKS & 242 & 3.1 & 11.4 & 61 & 69 & 6.2 \\
\hline
\end{tabular}

TABLE 3: Representative reported results on stereotactic radiosurgery and stereotactic radiotherapy

GKS = Gamma Knife Surgery, CKS = CyberKnife Surgery, FSRT = Fractionated Stereotactic Radiation Therapy, F/U = Follow-Up, N/A = Not Applicable

This treatment strategy is supported by the fact that this tumor responds relatively well to irradiation [2021]. The drawback of radiation is the possibility of its toxic effect on surrounding normal structures, but this adverse effect can be reduced by precise stereotactic irradiation of the target. Several studies have described the role of GKS for controlling craniopharyngiomas [8-14]. Hasegawa et al. reported that the five- and 10year PFS rates were $62 \%$ and $52 \%$, respectively, and Lee et al. described their 20 -year experience with GKS for craniopharyngioma and reported the volume of the treated tumor as a significant prognostic factor for the PFS $[8,13]$. Dho et al. demonstrated that the location of the tumor, the distance between the optic nerve and tumor, and the radiation dose were statistically significant, with an overall response rate [10]. Kobayashi et al. reported that a prescribed dose exceeding 13.2 Gy could be expected to achieve a better PFS than lower doses [14]. As in these studies, several other reports also suggest the efficacy of GKS for the management of this tumor. However, most of those studies were small series because of the low incidence of this disease. We, therefore, performed a multi-institutional study in our evaluation of 242 cases, making this the largest series to date. 
In the present study, we demonstrated the effectiveness of GKS for controlling residual and/or recurrent craniopharyngiomas, and, at the same time, showed the points to consider for achieving a better clinical course by this treatment strategy, namely, performing partial resection followed by GKS. The three-, five-, and 10 -year OS rates after GKS were 95.4\%, 92.6\%, and $82.1 \%$, respectively, whereas the PFS rates were $71.7 \%, 60.3 \%$, and $41.9 \%$, respectively. The OS rate seems to be acceptable, but the PFS rate leaves room for improvement.

While a higher radiation dose is expected to yield a stronger effect on the tumors, it may also carry an increased risk of adverse effects on the surrounding normal tissue. One advantage of GKS is the steep dropoff in radiation, which delivers sufficient irradiation to the target tissue while sparing the surrounding normal tissue. However, this advantage can only occur when the whole area of the tumor is adequately and precisely irradiated. Because if there is a part of a tumor that is not properly irradiated, it may receive an insufficient amount of irradiation to successfully control disease progression. Given that a sizeable portion of recurrence after GKS occurred in the outfield area of irradiation in the present study, it is important to properly recognize the area where the tumor exists, with consideration of the steep irradiation drop-off, in order to improve the PFS rate with GKS. Insufficient targeting might be one reason why the prescribed dose was not a significant factor influencing the PFS in this study.

Univariate analysis revealed the tumor volume and third ventricle involvement of the target tumor to be significant factors that influence the PFS. When the tumor grows, extending into the third ventricle, a larger area of the hypothalamus tends to become involved with the tumor. To prevent serious impairment of the hypothalamus, surgical manipulation at this site tends to be less aggressive, leading to a greater amount of residual tumor in this area, some of which might be difficult to identify during targeting due to surgical artifacts and other reasons on MRI. Furthermore, the locational proximity to the optic tract and the important function of the hypothalamus requires limiting the irradiation dose at the target tumor at this site. Generally, when tumors are located widely with an irregular shape, they tend to require more effort to identify the target's margin precisely. The difficulty and insufficient identification of the target tumor margin might contribute to an insufficient PFS rate. It goes without saying that, when developing a treatment plan for stereotactic irradiation, it is important to evaluate the extent of the target tumor location meticulously with imaging studies, such as MRI, taken not only at the time of planning but also before and after surgery on follow-up imaging and discuss the extent of the tumor border with the surgeons.

If the tumor is attached to an organ at risk (OAR), such as the optic pathway, which is vulnerable to radiation, it is difficult to deliver the ideal radiation dose to the target and avoid adverse effects, like radiation-induced optic neuropathy. Hasegawa et al. reported that radiation to the optic nerve exceeding 14 Gy might cause visual disturbance, even when delivered to a short segment of the nerve, and 10 Gy to a long segment may lead to optic neuropathy [13]. This report indicates that the optic pathway is more tolerable than previously thought, but when a tumor is close to or attaches to the optic pathway, the irradiation dose must be reduced to a dose that is too low to control the tumor. In addition, if the tumor is large, the irradiation dose needs to be kept low in order to avoid toxic effects on the surrounding normal tissue. In the present study, several cases required treatment of the target tumor with a reduced dose because of these reasons. This also seemed to contribute to an insufficient PFS rate.

To deliver sufficient irradiation to the target tumor while minimizing the toxic effects on the surrounding normal tissue is the key to better controlling a tumor. The adverse effects of irradiation on normal tissue can be reduced depending on the fraction. With the advent of new-generation GKS-the Gamma Knife Icon, which adopts mask fixation, fractionated GKS has become much more widely available. Fractionation is expected to reduce adverse effects on the optic pathway, hormonal function, and hypothalamic function. In the near future, fractionated irradiation might become the standard for GKS in treating craniopharyngioma.

In this study, the rate of radiation-induced complications was $6.2 \%$. This number is similar to that in previously reported series and seems to be relatively small, considering the critical location of the tumor. This is probably due to the accurate and relatively low-dose delivery of radiation to treat the tumors. However, at the final follow-up visit, more patients than this rate presented with a deterioration of the visual and hormonal function. While tumor progression is the primary factor that causes the impairment of important functions, such as visual, hormonal, and cognitive functions, the adverse effects of the treatments themselves also negatively affect these functions. In many cases in the present study, multiple treatments, including repeat surgery and repeat GKS, were employed to control the tumors. The longer the treatment course, the more patients tend to suffer from poor dysfunction caused by not only tumor progression but also the adverse effect of the treatments. Once important functions are impaired, it is almost impossible to restore them. Therefore, treatment should be performed as total management of the tumor, taking advantage of various modalities.

In pediatric patients harboring this tumor, the generation of secondary disorders, such as malignant tumor and vascular degeneration, is sometimes problematic in the long-term follow-up [22-23,28-29]. In addition, some studies have reported malignant changes in craniopharyngiomas during the course of treatment, which were suspected to have been caused by irradiation [30]. 
Because this tumor is pathologically benign, adverse effects in the long term should be discreetly considered, especially in pediatric patients. Avoiding irradiating, an excessively broad area is expected to reduce the early and late toxic effects on the surrounding organs and the possible generation of pathological conditions. Precise irradiation of the tumor by GKS following surgical resection with minimal invasion, which preserves the neurological and hormonal function, is key to achieving a better overall clinical course in patients with a craniopharyngioma.

\section{Study limitations}

Because this was a retrospective multi-institutional study, the criteria of SRS or radiosurgical techniques may have differed among institutes.

\section{Conclusions}

We herein described a multi-institutional study on the efficacy of GKS for craniopharyngiomas in our evaluation of 242 cases, the largest such series to date. In this study, we reported the following: 1) The three, five-, and 10-year overall survival rates after GKS were 95.4\%, 92.5\%, and 82.0\%, respectively. 2) The three-, five-, and 10-year PFS rates after GKS were $73.1 \%, 62.2 \%$, and $42.6 \%$, respectively. 3) Univariate analysis showed that the tumor volume and tumor location (extending to the third ventricle) were significantly correlated with the PFS. 4) The rate of radiation-induced complications was $6.2 \%$. GKS is effective in controlling the tumor growth of residual or recurrent craniopharyngiomas with an acceptable complication rate.

\section{Additional Information \\ Disclosures}

Human subjects: Consent was obtained by all participants in this study. Nagoya Kyoritsu Hospital IRB issued approval JLGK1303. Animal subjects: All authors have confirmed that this study did not involve animal subjects or tissue. Conflicts of interest: In compliance with the ICMJE uniform disclosure form, all authors declare the following: Payment/services info: All authors have declared that no financial support was received from any organization for the submitted work. Financial relationships: All authors have declared that they have no financial relationships at present or within the previous three years with any organizations that might have an interest in the submitted work. Other relationships: All authors have declared that there are no other relationships or activities that could appear to have influenced the submitted work.

\section{References}

1. Pekmezci M, Louie J, Gupta N, Bloomer MM, Tihan T: Clinicopathological characteristics of adamantinomatous and papillary craniopharyngiomas: University of California, San Francisco experience 1985-2005. Neurosurgery. 2010, 67:1341-1349. 10.1227/NEU.0b013e3181f2b583

2. Jane JA Jr, Laws ER: Craniopharyngioma. Pituitary. 2006, 9:323-326. 10.1007/s11102-006-0413-8

3. Bunin GR, Surawicz TS, Witman PA, Preston-Martin S, Davis F, Bruner JM: The descriptive epidemiology of craniopharyngioma. J Neurosurg. 1998, 89:547-551. 10.3171/jns.1998.89.4.0547

4. Lee $\mathrm{MH}$, Kim SH, Seoul HJ, et al.: Impact of maximal safe resection on the clinical outcome of adults with craniopharyngiomas. J Clin Neurosci. 2012, 19:1005-1008.

5. Mou J, Wang X, Huo G, et al.: Endoscopic endonasal surgery for craniopharyngiomas: a series of 60 patients . World Neurosurg. 2019, 124:e424-e430.

6. Baskin DS, Wilson CB: Surgical management of craniopharyngiomas. A review of 74 cases . J Neurosurg. 1986, 65:22-27. 10.3171/jns.1986.65.1.0022

7. Lindholm J, Nielsen EH: Craniopharyngioma: historical notes. Pituitary. 2009, 12:352-359. 10.1007/s11102008-0165-8

8. Lee CC, Yang HC, Chen CJ, et al.: Gamma Knife surgery for craniopharyngioma: report on a 20-year experience. J Neurosurg. 2014, 121:167-178. 10.3171/2014.8.GKS141411

9. Yomo S, Hayashi M, Chernov M, et al.: Stereotactic radiosurgery of residual or recurrent craniopharyngioma: new treatment concept using Leksell gamma knife model C with automatic positioning system. Stereotact Funct Neurosurg. 2009, 87:360-367. 10.1159/000236370

10. Dho YS, Kim YH, Kim JW, et al.: Optimal strategy of gamma knife radiosurgery for craniopharyngiomas . J Neurooncol. 2018, 140:135-143. 10.1007/s11060-018-2943-0

11. Niranjan A, Kano H, Mathieu D, Kondziolka D, Flickinger JC, Lunsford D: Radiosurgery for craniopharyngioma. Int J Radiat Oncol Biol Phys. 2010, 1:64-71. 10.1016/j.ijrobp.2009.07.1693

12. Ulfarsson E, Lindquist C, Roberts M, Rähn T, Lindquist M, Thorén M, Lippitz B: Gamma knife radiosurgery for craniopharyngiomas: long-term results in the first Swedish patients. J Neurosurg. 2002, 97:613-622.

13. Hasegawa T, Kobayashi T, Kida Y: Tolerance of the optic apparatus in single-fraction irradiation using stereotactic radiosurgery: evaluation in 100 patients with craniopharyngioma. Neurosurgery. 2010, 66:688694. 10.1227/01.NEU.0000367554.96981.26

14. Kobayashi T, Mori Y, Tsugawa T, et al.: Prognostic factors for tumor recurrence after gamma knife radiosurgery of partially resected and recurrent craniopharyngiomas. Nagoya J Med Sci. 2012, 74:141-147.

15. Lee MH, Kim SH, Seoul HJ, et al.: Impact of maximal safe resection on the clinical outcome of adults with craniopharyngiomas. J Clin Neurosci. 2012, 19:1005-1008. 10.1016/j.jocn.2011.09.033

16. Fahlbusch R, Honegger I, Paulus W, Huk W, Buchfelder M: Surgical treatment of craniopharyngiomas: 
experience with 168 patients. J Neurosurg. 1999, 90:237-250. 10.3171/jns.1999.90.2.0237

17. Honegger J, Buchfelder M, Fahlbusch R: Surgical treatment of craniopharyngiomas: endocrinological results. J Neurosurg. 1999, 90:251-257. 10.3171/jns.1999.90.2.0251

18. Yaşargil MG, Curcic M, Kis M, Siegenthaler G, Teddy PJ, Roth P: Total removal of craniopharyngiomas. Approaches and long-term results in 144 patients. J Neurosurg. 1990, 73:3-11. 10.3171/jns.1990.73.1.0003

19. Puget S, Garnett M, Wray A, et al.: Pediatric craniopharyngiomas: classification and treatment according to the degree of hypothalamic involvement. J Neurosurg. 2007, 106:3-12. 10.3171/ped.2007.106.1.3

20. Manaka S, Teramoto A, Takakura K: The efficacy of radiotherapy for craniopharyngioma . J Neurosurg. 1985, 62:648-656. 10.3171/jns.1985.62.5.0648

21. Kalapurakal JA, Goldman S, Hsieh YC, Tomita T, Marymont MH: Clinical outcome in children with craniopharyngioma treated with primary surgery and radiotherapy deferred until relapse. Med Pediatr Oncol. 2003, 40:214-218. 10.1002/mpo.10247

22. Hetelekidis S, Barnes PD, Tao ML, Fischer EG, Schneider L, Scott RM, Tarbell NJ: 20-year experience in childhood craniopharyngioma. Int J Radiat Oncol Biol Phys. 1993, 30:189-195. 10.1016/0360-3016(93)90227$\mathrm{m}$

23. Habrand JL, Ganry O, Couanet D, Rouxel V, Levy-Piedbois C, Pierre-Kahn A, Kalifa C: The role of radiation therapy in the management of craniopharyngioma: a 25-year experience and review of the literature. Int J Radiat Oncol Biol Phys. 1999, 44:255-263. 10.1016/s0360-3016(99)00030-9

24. Harrabi SB, Adeberg S, Welzel T, Rieken S, D, Debus J, Combs SE: Long term results after fractionated stereotactic radiotherapy (FSRT) in patients with craniopharyngioma: maximal tumor control with minimal side effects. Radiat Oncol. 2014, 16:203. 10.1186/1748-717X-9-203

25. Hashizume C, Mori Y, Kobayashi T, Shibamoto Y, Nagai A, Hayashi N: Stereotactic radiotherapy using Novalis for craniopharyngioma adjacent to optic pathways. J Neurooncol. 2010, 98:239-247. 10.1007/s11060-010-0180-2

26. Minniti G, Saran F, Traish D, et al.: Fractionated stereotactic conformal radiotherapy following conservative surgery in the control of craniopharyngiomas. Radiother Oncol. 2007, 82:90-95.

27. Iwata H, Tatewaki K, Inoue M, et al.: Single and hypofractionated stereotactic radiotherapy with CyberKnife for craniopharyngioma. J Neurooncol. 2012, 106:571-577. 10.1007/s11060-011-0693-3

28. Regine WF, Mohiuddin M, Kramer S: Long-term results of pediatric and adult craniopharyngiomas treated with combined surgery and radiation. Radiother Oncol. 1993, 27:13-21. 10.1016/0167-8140(93)90039-b

29. Varlotto JM, Flickinger JC, Kondziolka D, Lunsford LD, Deutsch M: External beam irradiation of craniopharyngiomas: long-term analysis of tumor control and morbidity. Int J Radiat Oncol Biol Phys. 2002, 54:492-499. 10.1016/s0360-3016(02)02965-6

30. Virik K, Turner J, Garrick R, Sheehy JP: Malignant transformation of craniopharyngioma. J Clin Neurosci. 1999, 6:527-530. 10.1016/s0967-5868(99)90019-X 